\title{
EMPODERAMENTO FEMININO: UM ESTUDO COM MULHERES EMPREENDEDORAS
}

Rafaela Silva Mâncio ${ }^{1}$

Silvana Alves De Oliveira ${ }^{1}$

Felipe Gouvêa Pena ${ }^{1}$

${ }^{1}$ Centro Universitário de Belo Horizonte 


\section{EMPODERAMENTO FEMININO: UM ESTUDO COM MULHERES EMPREENDEDORAS}

\section{Resumo:}

Verifica-se que a mulher tem assumido um papel cada vez mais importante no empreendedorismo e no mercado de trabalho, diante disso, esse trabalho buscou identificar as trajetórias das mulheres empreendedoras, através de uma pesquisa, com o objetivo de relatar como mulheres empreendedoras percebem o próprio desenvolvimento e o empoderamento feminino na sociedade contemporânea. A pesquisa assumiu uma abordagem qualitativa e caracterizou-se como um estudo descritivo, a coleta de dados se deu por meio de entrevistas semiestruturadas aplicadas à 15 mulheres empreendedoras. Os resultados demonstram que as ações de empoderamento feminino auxiliam no desenvolvimento das mulheres empreendedoras, que estão aos poucos ganhando espaço, vez e voz dentro e fora do mercado de trabalho. Entretanto, embora as entrevistadas acreditem que o empoderamento feminino seja fundamental para o desenvolvimento das mulheres no mercado percebe-se que os homens ainda possuem mais oportunidades profissionais e maior possibilidade de progredir na carreira do que elas.

Palavras-chave: empoderamento; empoderamento feminino; empreendedorismo; trabalho.

\section{$1 \quad$ Introdução}

Com o passar dos anos, o pensamento de que as mulheres nasceram destinadas a serem "donas de casa" enquanto os homens sustentavam o lar passou a mudar. A partir dos anos 70, a mulher brasileira começou a ocupar um espaço antes só ocupado pelos homens, adentraram no mercado de trabalho em um contexto de expansão econômica, industrial e social (CABRAL, 1999). A mulher passou a investir em si mesma e na sua formação, ganhando espaço e respeito na sociedade e no mercado de trabalho.

Em busca de superar a desigualdade de gênero que era muito forte no passado e ainda está presente na sociedade atualmente, as mulheres passaram a buscar oportunidades no mercado de trabalho, crescer dentro das organizações e alcançar postos antes pouco prováveis, como gestoras de nas organizações. Algumas foram além e decidiram constituir o próprio empreendimento.

Dados do Global Entrepreneurship Monitor (GEM, 2015) revelam que as mulheres representam cerca de $49 \%$ dos empreendedores iniciais no Brasil. Pesquisas dessa mesma instituição, indicam que a mulher brasileira é uma das mais empreendedoras do mundo.

Vários fatores levam as mulheres a investir como empreendedora, considerando que em um mundo onde temas como o feminismo e a valorização da mulher no mercado de trabalho é visto como vitimismo por parte da sociedade, investir na própria carreira, empreender e inovar é um caminho encontrado por muitas, seja para aumentar a renda por necessidade e/ou aproveitar uma oportunidade de mercado. "O empoderamento é um processo dirigido para a transformação da natureza e direção das forças sistêmicas que marginalizam as mulheres e outros setores excluídos em determinados contextos" (BATLIWALA, 1994 apud SARDENBERG, 2009, p. 6). Nesses termos, o empoderamento feminino está cada vez mais 
presente para assegurar que as mulheres e os homens gozem dos mesmos direitos e, consequentemente, dar voz e elevá-las, já que muitas vezes são subestimadas como pessoas e profissionais.

Diante desse contexto, o problema de pesquisa busca responder: "como as mulheres empreendedoras percebem o próprio desenvolvimento e o empoderamento feminino na sociedade contemporânea?

Propõe-se, portanto, como objetivo geral relatar como mulheres empreendedoras percebem o próprio desenvolvimento e o empoderamento feminino na sociedade contemporânea, a partir da elucidação dos seguintes objetivos específicos: (I) identificar quais as dificuldades enfrentadas por mulheres empreendedoras no mercado de trabalho; (II) demonstrar a importância do empoderamento das mulheres para a construção de uma sociedade igualitária no quesito social/econômico; e por fim, correlacionar o empoderamento feminino com o desenvolvimento das mulheres empreendedoras.

Este artigo se torna justificável por contribuir com os estudos na área de ciência social e mostrar a relevância do empoderamento feminino na vida das mulheres, no caso em estudo, as empreendedoras.

Dados de um estudo do Serviço Brasileiro de Apoio às Micro e Pequenas Empresas (SEBRAE, 2015), divulgado em 2015 apontam que o empreendedorismo feminino no Brasil cresceu em 14 anos cerca de 34\%, são mais de 7,3 milhões de mulheres empreendedoras. Isso representa $31,1 \%$ do total de 23,5 milhões de empreendedores que empregam no país. Se compararmos esses dados com a história de luta por igualdade entre homens e mulheres vivida ao decorrer dos anos, observa-se que o empoderamento das mulheres vem ganhando força, pois é fundamental para o desenvolvimento econômico, social e cultural, já que as ações de empoderamento feminino estimulam uma série de benefícios como a igualdade salarial e de oportunidades no mercado de trabalho, acesso igualitário à educação independente do gênero, além de promover a desvinculação da imagem de mulheres apenas como donas de casa, trazendo reflexos positivos para as próximas gerações.

\section{$2 \quad$ Referencial Teórico}

Esta seção é composta por três subcapítulos: empoderamento, empoderamento feminino e empreendedorismo feminino.

\subsection{Empoderamento}

Conforme Costa e D’Oliveira (2013, apud Strey e Cúnico, 2016), o uso da palavra "empoderamento" foi ampla nos Estados Unidos em 1970, com os movimentos dos negros para conquistar a cidadania. Na mesma época, o termo passou a ser utilizado em movimentos feministas, porém, com uma conceituação diferente. $\mathrm{O}$ empoderamento era visto como a mudança das ações e das estruturas, com o objetivo de mitificar a posição subalternizada das mulheres enquanto gênero.

O empoderamento na visão de Strey e Cúnico (2016) se torna viável em decorrência das trocas adquiridas durante as interações com as pessoas ao nosso redor e com o grupo. Ele começou a ser abordado no sentido de emancipação social, em que a autoestima dos membros de certos grupos da sociedade era elevada. O empoderamento é um termo que possui como um dos sentidos elevar a autonomia, tanto individual quanto coletiva, e pode conter vários significados dependendo do contexto que for empregado. 
É através da conscientização e da reflexão prática que as pessoas vão empoderando-se e tornando-se capazes de decidir os rumos da própria vida. "Empoderar os sujeitos é equilibrar as relações de poder em favor daqueles que têm menos recursos, porquanto o empoderamento está sobejamente correlacionado à equidade" (STREY; CÚNICO, 2016 p.18).

De acordo com as autoras, pode-se dizer que o empoderamento é um catalisador da inclusão social, e que empoderar significa conquistar espaço, vez e voz, seja por pessoas, empresas, comunidades, de forma com que cada indivíduo obtenha autonomia e capacidade de fazer escolhas sociais, políticas e econômicas.

\title{
2.2 Empoderamento Feminino
}

No Brasil, de acordo com Camargo (2013), observa-se diversas situações de desigualdade social, e uma delas é em relação ao gênero, iniciando a partir desse ponto, as representações sociais referentes à mulher sendo uma figura ativa da vida em sociedade.

De acordo com Gomes (2017) o empoderamento feminino começou a ser trilhado ao redor do mundo em 1911, com a criação do Dia Internacional da Mulher em decorrência de um incêndio que ocasionou a morte de mais de cem operárias em Nova York. No ano de 1932, as mulheres brasileiras conquistaram o direito ao voto opcional, porém, apenas mulheres casadas com a autorização do marido, viúvas e solteiras com renda própria. Em 1946 o voto se tornou obrigatório para todas as mulheres assim como para os homens.

Conforme Strey e Cúnico (2016), uma das primeiras conceituações femininas diante do empoderamento surgiu nos anos de 1970, com o movimento "Women In Development" (Mulheres em Desenvolvimento). Era tido um conceito de empoderamento ligado ao controle sobre os outros e sobre os recursos, então, para que houvesse o empoderamento, quem tivesse "poder" deveria ser destituído da posição, ou seja, para uns ganharem outros teriam que perder, o poder seria tomado por alguém empoderado, nesse caso, as mulheres, gerando indignação por quem se sentia ameaçado. Era mantida a lógica da estruturação de poder na sociedade, em que uns possuem e outros não, porém essa distribuição não era tão questionada.

\begin{abstract}
Diferentemente do que pregavam correntes feministas antigamente, as mulheres hoje já não se consideram apenas vítimas. Querem ser protagonistas. Pretendem transformar a sociedade "empoderando" as mulheres, desde meninas, e combatendo o machismo em todas as manifestações, contando inclusive com o apoio dos homens, seus aliados (PINSKY; PEDRO, 2017, p. 120).
\end{abstract}

Segundo Strey e Cúnico (2016 p. 14) o empoderamento feminino "reflete o modo como as mulheres assumem sua condição de sujeito por intermédio de conscientização, de participação e de igualdade". Na opinião das autoras, o empoderamento é fundamental, principalmente para que se possa exigir mais igualdade via políticas públicas. $\mathrm{O}$ empoderamento feminino representa, portanto, um embate à desigualdade de gênero e ao poder dominante masculino na sociedade, e as ações de empoderamento representam uma mudança nessa dominação sobre as mulheres, garantindo a elas uma autonomia em todos os sentidos, sejam eles referentes ao direito de ir e vir, quanto ao controle dos seus corpos e da sua sexualidade.

Leis referentes a igualdade de gênero começaram a surgir entre os anos de 1970 e 1980, em contrapartida das lutas por liberdades democráticas e maior participação feminina na sociedade. Os movimentos de mulheres e do feminismo foram marcantes na década de 80 , por 
meio dos "grupos de consciência" e das manifestações de rua. Nas universidades começou a ser discutido o "problema de mulher" e a conceituação de gênero embasada nas percepções das diferenças sexuais diante da construção social. Em 1988, momento em que a Constituição estava sendo elaborada, boa parte das reivindicações das mulheres obteve reconhecimento. Dentre as reivindicações atendidas, constava a igualdade entre homens e mulheres no âmbito familiar, a licença a maternidade foi ampliada sem impactar o emprego e o salário, e, além disso, foi criada a licença-paternidade é proibida a desigualdade salarial baseada no gênero. A partir de 1992 as mulheres começaram a ser permitidas no Exército. Desde 1995, os empregadores são proibidos por lei de discriminarem as mulheres durante as contratações e no ambiente de trabalho, no mesmo ano, uma lei passou a vigorar exigindo uma cota mínima de $20 \%$ para candidaturas de mulheres nos partidos políticos, sendo que em 1997 subiu para 30\%. No ano de 1998, uma mulher foi eleita pela primeira vez para um governo estadual e em 2001 a primeira juíza foi empossada no Supremo Tribunal Federal. Em 2010, uma mulher foi eleita como presidente da República sendo reeleita em 2014. As mulheres foram conquistando aos poucos o espaço público, e hoje em dia, alegar que elas não são tão capazes quanto o sexo oposto causa revolta (PINSKY; PEDRO, 2017).

\subsection{Empreendedorismo Feminino}

Segundo Borelli e Matos (2012), entre 1917 e 1919, surgiram às primeiras medidas regulamentadoras do trabalho feminino, após reivindicação através de mobilizações e paralisações das fábricas. Essas medidas proibiam a jornada noturna e o trabalho durante o último mês de gestação e o primeiro após o parto. Entretanto, causaram discussões, pois na tentativa de proteger as mulheres por considerá-las mais frágeis e vulneráveis, provocaram demissões e dificultaram o acesso das mulheres ao mercado de trabalho devido às mesmas passarem a ser vistas como mais onerosas pelos empregadores.

Borelli e Matos (2012, p.127) afirmam, ainda, que fatores variados levaram as mulheres a assumirem funções produtivas, ocupando brechas no mercado de trabalho ou atingindo colocações antes vetadas ou inacessíveis. As mulheres eram facilmente colocadas para trabalhar nas funções de fiar, tecer, costurar, cuidar e servir e tinham maiores dificuldades em adentrar em setores masculinizados. "Alguns confundem "trabalho feminino" com as funções domésticas, os cuidados com a família e a casa; já outros entendem que ele envolve as atividades remuneradas realizadas no próprio domić́lio e mesmo a participação das mulheres" no mercado. De acordo com as autoras, "o trabalho chegou a ser questionado como elemento impeditivo das ditas "funções naturais" das mulheres, as de mãe e esposa". Uma das maiores mudanças ocorridas nas últimas décadas foi a presença evidente das mulheres no mercado de trabalho.

De acordo com Camargo (2013), nas últimas décadas do século XX, a inserção da mulher no mercado de trabalho foi cada vez maior, graças a fatores econômicos, culturais e sociais. "Em razão do avanço e crescimento da industrialização no Brasil, ocorreram a transformação da estrutura produtiva, o contínuo processo de urbanização e a redução das taxas de fecundidade nas famílias, proporcionando a inclusão das mulheres no mercado de trabalho". Para o autor, independentemente do gênero, quanto maior o nível de escolaridade, mais chances uma pessoa possui de inclusão no mercado de trabalho, além disso, as mulheres estão tendo maior presença no mercado e ocorreu uma melhora entre as diferenças salariais entre elas e os homens. Entretanto, ainda existem dificuldades para mulheres assumirem cargos de liderança e 
igualdade salarial com relação aos homens que exercem a mesma função e ocupam o mesmo cargo.

Embora tenham hoje maiores oportunidades e mais direitos que três décadas atrás, as mulheres brasileiras em comparação com os homens, em média, ainda são mais pobres, recebem menores salários e abraçam maiores responsabilidades familiares e domésticas - no cuidado da casa, das crianças, dos idosos e doentes -, mesmo que sejam provedoras (PINSKY; PEDRO, 2017, p. 111).

Segundo as autoras Pinsky e Pedro (2017 p. 121), "a busca pelo mercado de trabalho por parte das mulheres não representa apenas a luta por autonomia, indica, também, o empobrecimento das famílias cuja sobrevivência exige a colaboração de todos" para o estimado orçamento doméstico. Apesar da desigualdade, as mulheres vêm alcançando grande visibilidade em diversas áreas como na mídia, na política, no mercado de trabalho, cargos de chefia, nas universidades, entre outras.

\begin{abstract}
No mercado de trabalho, ainda há mais homens que mulheres, ocupados (aproximadamente 1,5 homens para cada mulher). Em média os homens estão nos postos mais bem remunerados, enquanto a maior parte das mulheres se concentra em ocupações de menor remuneração, em empregos mais precários (de tempo parcial, terceirizados e/ou feitos no domicílio) e mais vulneráveis às crises econômicas. $\mathrm{A}$ diferença de salários entre homens e mulheres ocorre em todas as classes e se amplia nas faixas de remuneração mais alta. Contudo, mesmo ganhando menos do que os homens, as mulheres são chefes de quase um terço dos domicílios brasileiros (PINSKY; PEDRO, 2017, p. 120).
\end{abstract}

Um estudo realizado pelo instituto Ethos (2016) com as 500 maiores empresas do Brasil visando mapear o perfil social, racial e de gênero das empresas brasileiras, corrobora com Pinsky e Pedro (2017), pois, observou-se que as estruturas organizacionais apresentam um "afunilamento hierárquico", ou seja, uma menor inclusão de mulheres em cargos mais estratégicos das organizações, conforme Figura 1.

Figura 1 - Distribuição do pessoal por sexo (\%)

\begin{tabular}{lcc} 
& HOMENS & MULHERES \\
\hline Conselho de Administração & 89,0 & 11,0 \\
\hline Quadro Executivo & 86,4 & 13,6 \\
\hline Gerência & 68,7 & 31,3 \\
\hline Supervisão & 61,2 & 38,8 \\
\hline Quadro Funcional & 64,5 & 35,5 \\
\hline Trainees & 57,4 & 42,6 \\
\hline Estagiários & 41,1 & 58,9 \\
\hline Aprendizes & 44,1 & 55,9 \\
\hline
\end{tabular}

Fonte: Instituto Ethos (2016).

Vale ressaltar, contudo, que a inclusão das mulheres no mercado de trabalho vem aumentando, isso se deu por que as mulheres passaram a colocar a carreira em primeiro lugar, 
antes da função de procriar durante a década de 70, passaram a estudar mais e a quantidade das mesmas nas universidades aumentou significativamente. Através da autoconscientização e autovalorização, as mulheres começaram a se sentir capazes de gerenciar suas próprias carreiras. No século XXI, as mudanças no pensamento humano referentes ao desenvolvimento da carreira da mulher começaram a ocorrer. O pensamento de que era necessária força física para adentrar nas organizações, foi trocado pelo pensamento da necessidade de preparo intelectual, conhecimento e inovação, independente do sexo do profissional (MANDELLI, 2015). Embora, conforme Moreno (2016, p. 22):

[...] entraram pela porta dos fundos no mundo do trabalho, tendo de "provar" que mereciam a "oportunidade" que thes estava sendo oferecida, sempre que o mercado se via com falta de mão de obra em algum setor específico, embora muitas vezes estivessem mais atraídas por outro setor, que oferecesse melhores condições de trabalho. Começaram entrando em profissões que, de alguma maneira, representassem uma extensão do trabalho doméstico. Se, em casa, cuidavam da faxina ou do fogão, viraram faxineiras ou empregadas domésticas, cozinheiras, lavadeiras e similares. Se, em casa, cuidavam da educação dos filhos, passaram a ser babás e, no topo, professoras. E assim foi.

Todavia, as mulheres estão assumindo cada vez mais posições marcantes no cenário social e econômico (PEQUENAS EMPRESAS \& GRANDES NEGÓCIOS, 2017). Nos últimos anos, segundo a pesquisa Global Entrepreneurship Monitor (GEM, 2016), aumentou em mais de $30 \%$ o número de empreendedoras no Brasil.

Para Biagio (2012), empreendedorismo significa praticar algo novo, executar uma nova ideia, ou agregar valor a um produto ou processo que já existe, atingindo um objetivo/resultado. Para Degen (2009), empreendedor é quem tem a visão do negócio e realiza o empreendimento.

Segundo Alvim (2012), o crescimento de mulheres empreendedoras no Brasil e no mundo vem se tornando cada vez mais um fenômeno relevante para os âmbitos sociais e econômicos e precisa ser acompanhado e apoiado.

De acordo com a pesquisa Global Entrepreneurship Monitor (GEM, 2016), divulgada pelo Sebrae, $31 \%$ das empresas no país são geridas por mulheres, que possuem uma taxa de empreendedorismo elevada em comparação a dos homens: $15,4 \%$ contra $12,6 \%$. A pesquisa indica que $48 \%$ das empreendedoras iniciam a atividade empresarial porque precisam complementar a renda ou buscam recolocação no mercado de trabalho. O presidente do Sebrae, Guilherme Afif Domingos afirma que o movimento de empoderamento feminino vem crescendo na política, na iniciativa privada e à frente dos negócios. As mulheres empreendem para gerar renda e atender às próprias demandas (SEBRAE, 2018).

Ao que indicam pesquisas e análises realizadas pelo Sebrae (2018), a quantidade de mulheres que começaram a empreender cresceu muito, porém das empresas comandadas por mulheres, apenas uma pequena parcela é considerada de alto impacto, e menos de $10 \%$ recebem investimentos externos, diferentemente das empresas comandadas pelo sexo oposto, que recebe um maior auxílio financeiro. A maioria das mulheres empreendedoras enfrentam barreiras sociais e econômicas no percurso do sucesso da própria organização, fazendo com que o empreendimento se torne mais desafiador. Ainda sofrem julgamentos em relação aos homens, que são vistos como mais aptos com relação a negócios, e essa discriminação dificulta as mulheres a encontrar um ambiente favorável para progredir. Pode-se notar a baixa presença de mulheres em setores como tecnologia e informática, que mesmo com avanços tecnológicos, são 
setores masculinizados, e de acordo com uma pesquisa realizada em 2015 pela mesma instituição, a participação feminina nesses setores caiu em aproximados $19 \%$.

A pesquisa ainda revelou que apesar de $80 \%$ dos empreendedores considerarem importante a valorização da mulher nas empresas e fazer com que as mesmas sintam atraídas por cargos de liderança, somente $13 \%$ acreditam que essas mudanças realmente irão acontecer, e essa falta de motivação no ambiente de trabalho acaba se tornando um empecilho para que mais mulheres abram a própria empresa, visto nos dados que $43 \%$ das mulheres veem o medo do fracasso como o principal motivo para não empreenderem. A desvalorização da mulher no ambiente de trabalho também é responsável pela redução no número de mulheres que querem crescer dentro das empresas, subir de cargo. Depois de anos na mesma posição, elas acabam se conformando com a posição que ocupam por acreditarem não serem capazes ou não possuírem habilidades suficientes para serem promovidas.

$\mathrm{Na}$ opinião de Mandelli (2015), as mulheres têm grande importância na estratégia organizacional, pois tratam a diversidade corporativa de forma natural, além de colocarem em prática suas habilidades de realizarem diferentes papéis que exercem no dia a dia, com muito foco em desenvolvimento de pessoas, devido a sensibilidade feminina, que pode vir a permitir que a equipe trabalhe em sintonia, obtendo soluções criativas para certas questões.

\begin{abstract}
A equipe que sonha, que tem uma visão clara e concisa, que tem objetivos e que é motivada e engajada traz melhores resultados. A motivação para fazer diferente e atingir outros patamares traz um combustível sensacional para o ambiente organizacional, e o líder feminino, com todo seu cuidado, conhecimento e visão multifacetada, tem grande facilidade em promover o sonho e consequentemente a motivação da equipe (MANDELLI, 2015, p.32).
\end{abstract}

Segundo Costa (2018), o preconceito no meio empresarial é algo a mais nos desafios da mulher empreendedora, devido a vivermos em um mundo onde muitos desconfiam e colocam em prova a proatividade e as competências das mulheres. De acordo com a autora, apesar das mulheres enfrentarem diversos desafios, isso faz com que elas ganhem força e sejam empoderadas. Para a autora, é preciso força de vontade e engajamento para empreender, além de um preparação para o que pode vir a acontecer, para mitigar os desafios que podem surgir no caminho, como o julgamento desigual, tendo em vista que os homens são considerados mais capacitados no domínio dos negócios do que as mulheres; o medo de fracassar, causado pelas críticas e dúvidas em relação a capacidade das empreendedoras; a falta de apoio, já que no mundo dos negócios o destaque ainda é para o sexo masculino; e o equilíbrio entre a vida profissional e familiar, em alguns momentos deve-se sacrificar momentos pessoais independente do gênero, para alcançar objetivos. Um dos conselhos ofertados pela autora é que mulheres encontrem apoio umas com as outras, uma empoderando a outra e incentivando em seus caminhos, para dar fim a qualquer tipo de preconceito.

\title{
$3 \quad$ Metodologia
}

A pesquisa caracteriza-se como estudo descritivo, por meio de pesquisa bibliográfica e estudo de caso e a análise que foi baseada em fonte primária. O estudo descritivo observa, registra, analisa e ordena dados, sem manipulá-los. Tem como objetivo analisar a frequência, natureza entre outras características do fato através de dados coletados por meio de entrevistas, formulários, questionários, testes, observação, entre outras técnicas (PRODANOV; FREITAS, 2013). 
A pesquisa bibliográfica é realizada com o objetivo de analisar o que está sendo investigado, por meio de teorias sobre o tema (CHIARA et al., 2008). Já o estudo de caso, é um estudo profundo que permite o conhecimento amplo e detalhado do seu objeto (GIL, 2008). Fonte primária são os dados colhidos pelo próprio autor da pesquisa (MEDEIROS, 2000).

Através de uma abordagem qualitativa, a pesquisa teve como objeto de estudo mulheres empreendedoras, sendo que as mesmas foram escolhidas pelo critério de conveniência, vale ressaltar que a proximidade entre pesquisadores e pesquisadas visou criar uma ambiência em que as mulheres empreendedoras se sentissem à vontade para conversar sobre os assuntos abordados.

Vale ressaltar, que a pesquisa qualitativa leva à compreensão pontuada pela interpretação dos fatos sociais, o ato determinante do discurso acadêmico (TOMAINO et al., 2016).

A amostra, por sua vez, se configurou como não probabilística, ou seja, não foram utilizadas formas aleatórias e tão pouco fórmulas estatísticas na determinação do número de pesquisados (MARCONI; LAKATOS, 2011).

Foram entrevistadas 15 mulheres $(\mathrm{E} 1, \mathrm{E} 2, \mathrm{E} 3 . . . \mathrm{E} 15)$ a partir de um roteiro estruturado com o objetivo de analisar como elas percebem o próprio desenvolvimento e o empoderamento feminino na sociedade contemporânea, e atingir os objetivos específicos da pesquisa.

O tratamento dos dados oriundos das entrevistas se deu a partir da análise descritiva, contemplando a descrição, a análise e a interpretação dos mesmos. Sendo que, na descrição eles foram organizados considerando-se cada um dos entrevistados, analisados a partir de uma leitura atenta visando à compreensão do conteúdo evidenciado em cada uma das questões submetidas às pesquisadas e, por fim, os dados foram interpretados a partir da elaboração de uma síntese entre a teoria e os dados primários, ou seja, buscou-se criar um diálogo entre os diversos estudos existentes acerca do tema e as narrativas das entrevistadas (GOMES et al. 2005).

\section{$4 \quad$ Análise dos Dados}

Esse trabalho tem por objetivo geral relatar como as mulheres empreendedoras percebem o próprio desenvolvimento e o empoderamento feminino na sociedade contemporânea. Os objetivos específicos buscaram informar quais as dificuldades enfrentadas por mulheres empreendedoras no mercado de trabalho, demonstrar a importância do empoderamento das mulheres para a construção de uma sociedade igualitária no quesito social/econômico e correlacionar o empoderamento feminino com o desenvolvimento das mulheres empreendedoras.

Neste estudo, entrevistou-se 15 empresárias identificadas como E1, E2, E3...e E15, cujo ramos das empresas são: alimentação (E1, E14, E15), fotografia (E12), academia (E3), roupas (E2, E4, E8), entretenimento (E5, E13), beleza (E6, E7), saúde (E9), pet shop (E10) e suplementação (E11).

Seguindo um roteiro de entrevista, realizou-se uma transcrição das informações com posterior análise de conteúdo descritiva nos moldes de Melo et al. (2007).

\subsection{Perfil das Entrevistadas}

Através da entrevista realizada com a amostra de 15 mulheres empreendedoras objetos da pesquisa, pode-se descrever o perfil das mesmas por meio de questionamentos realizados durante a entrevista. 
Das 15 mulheres entrevistadas, 5 (E2, E3, E4, E8 e E10 - 33,3\%) atuam com outra atividade profissional além da carreira de empreendedoras, na qual 2 frequentemente (E10 e E8 - 13,3\%), 2 (E4 e E2 - 13,3\%) raramente e 1 (E3 - 6,7\%) nunca pensaram em se demitir. 10 mulheres atuam apenas como empresárias (E1, E5, E6, E7, E9, E11, E12, E13, E14 e E15), representando $66,7 \%$. Dentre os 33,3\% das mulheres que atuam com outra atividade profissional, 13,3\% (E8 e E10) enfrentam dificuldades mas conseguem pagar as contas e ainda fazem uma poupança no fim do mês, enquanto 2 (E2 e E4) ganham o necessário para ter uma boa qualidade de vida e 1 (E3) consegue pagar as contas e satisfazer seus desejos.

Com relação a idade, 2 possuem até 25 anos (E2 e E8), 6 possuem de 26 a 30 anos (E3, E6, E9, E10, E12 e E15), 4 entre 31 a 35 anos (E4, E5, E11 e E14), 2 entre 36 a 40 anos (E7 e E13) e 1 com mais de 51 anos (E1). Em relação a quanto tempo estão no mercado de trabalho, 1 respondeu de 1,1 a 2 anos (E2), 1 de 2,1 a 5 anos (E8), 8 de 5,1 a 10 anos (E3, E4, E5, E6, E9, E10, E12 e E15), 1 de 10,1 a 15 anos (E11), 3 de 15,1 a 20 anos (E7, E13 e E14) e 1 possui mais de 25,1 anos (E1) no mercado. Quando questionadas sobre o tempo que possuem o empreendimento, 2 possuem há menos de 1 ano (E2 e E10), 1 possui entre 1,1 a 2 anos (E8), 7 possuem entre 2,1 a 5 anos (E3, E4, E5, E6, E9, E12 e E15), 2 possuem entre 5,1 a 10 anos (E11 e E14), 2 entre 10,1 a 15 anos (E7 e E13) e 1 possui há mais de 25,1 anos (E1).

Dentre as 15 entrevistadas, 7 mulheres (E3, E4, E7, E9, E11, E12 e E15 - 46,7\%) empreenderam por necessidade e 8 (E1, E2, E5, E6, E8, E10, E13 e E14 - 53,3\%) porque tinham como sonho ter o seu próprio negócio.

Das entrevistadas, 10 empreendedoras (E1, E2, E3, E4, E5, E6, E7, E8, E9 e E10 - 66,7\%) possuem apenas o ensino superior completo e 5 (E11, E12, E13, E14 e E15 - 33,3\%) se especializaram em algo.

Dentre a amostra, 6 mulheres são casadas (E1, E4, E5, E6, E12 e E14), 7 solteiras (E2, E3, E8, E9, E10, E11 e E15) e 2 divorciadas (E7 e E13). As casadas foram questionadas se os companheiros auxiliam nas tarefas domésticas, 2 responderam que sim (E6 e E12) e 4 responderam não (E1, E4, E5 e E14). 5 mulheres (E1, E4, E6, E7 e E13 - 33,3\%) possuem filhos sendo que 4 têm com quem deixar para ir trabalhar e 1 (E6) não. Questionadas se o fato de ter filhos dificultou o desenvolvimento profissional, 3 responderam que sim (E6, E7 e E13) e 2 que não (E1 e E4). Para as mulheres que não possuem filhos, foi questionado se o fato de não ter filhos ajudou no desenvolvimento profissional e elas responderam que sim (E2, E3, E5, E8, E9, E10, E11, E12, E14 e E15).

Questionadas sobre as dificuldades de trabalhar, ser mãe e mulher ao mesmo tempo, as mulheres que se enquadram nesse perfil afirmaram que administrar o tempo juntamente com o acúmulo de tarefas são uma das maiores dificuldades (E1, E4 e E6).

Em relação a quem é o maior provedor do lar, 1 respondeu que é o marido (E1), 3 que a mulher e o marido são igualmente os provedores do lar (E6, E12 e E14), enquanto 11 afirmam que elas são as maiores provedoras (E2, E3, E4, E5, E7, E8, E9, E10, E11, E13 e E15).

Em relação a conciliação da vida profissional com a pessoal, 6 mulheres afirmaram não conseguir conciliar (E3, E4, E5, E6, E7 e E13), enquanto 9 afirmaram que conseguem (E1, E2, E8, E9, E10, E11, E12, E14 e E15).

Quando questionadas se já sofreram preconceito ou discriminação por serem mulheres, apenas 1 entrevistada afirmou que não (E1), representando 6,67\% das entrevistadas. 8 mulheres 
afirmaram já ter escutado piadas durante algum momento da carreira (E2, E3, E4, E5, E7, E8, E10 e E11), enquanto 7 afirmaram que não (E1, E6, E9, E12, E13, E14 e E15).

Perguntadas se sentem-se pressionadas por serem mulheres e ocuparem tal posição dentro da organização, 12 afirmaram que não (E1, E4, E5, E6, E7, E9, E10, E11, E12, E13, E14 e E15 - 80\%), enquanto 3 (E2, E3 e E8 - 20\%) afirmaram que em alguns momentos sim.

Quando questionadas se ser empreendedora é para mulheres e se consideram-se empoderadas, $100 \%$ responderam que sim.

\subsection{Desenvolvimento e Empoderamento Feminino}

Nesse subtópico buscou-se evidenciar a percepção das pesquisadas sobre o seu desenvolvimento e o empoderamento feminino na sociedade contemporânea, constando-se que todas consideram-se exemplos para outras mulheres, deixando claro sobre os esforços que fizeram para conquistar tal patamar profissional. A maioria das entrevistadas não possuíam condições de investir no momento em que desejavam, então, algumas tiveram que adiar os planos e poupar um pouco do que ganhavam para poder abrir o negócio próprio, enquanto outras realizaram trabalhos extras para conseguir mais dinheiro, já que no emprego que tinham antes de se tornarem empreendedoras não ganhavam o suficiente para investir. A E15, por exemplo, não recebia o suficiente para se sustentar e precisava arrumar trabalhos extras para se manter. Como não tinha oportunidade de crescimento profissional no emprego, contou com a ajuda dos pais para abrir seu empreendimento.

Perguntadas se os homens possuem mais oportunidades profissionais e maior possibilidade de progredir na carreira por serem homens, todas responderam que sim, citando que enxergam mais homens em cargos de chefia do que mulheres, homens recebendo mais do que mulheres mesmo exercendo a mesma função, áreas profissionais que são masculinizadas e o machismo que ainda existe dentro das organizações e na sociedade.

Pode-se alinhar as informações colhidas das entrevistas com as das autoras Pinsky e Pedro (2017). As mulheres entrevistadas acreditam que os homens estão mais presentes no mercado de trabalho, estando em cargos mais bem remunerados enquanto as mulheres estão na maior parte em empregos mais precários e vulneráveis às crises econômicas, sem falar sobre a diferença salarial existente.

Essa percepção das entrevistadas coaduna com o estudo realizado pelo instituto Ethos (2016, p. 17), com as 500 maiores empresas do Brasil, visando mapear o perfil social, racial e de gênero das empresas brasileiras, evidenciou-se que, as estruturas organizacionais apresentam um "afunilamento hierárquico". Percebe-se, portanto, uma menor inclusão de mulheres em cargos mais estratégicos das organizações. Os dados demonstraram que as mulheres perdem 7,5 pontos percentuais dos cargos de supervisão às gerências, das gerências aos cargos de diretorias perdem mais 18 pontos percentuais e nos conselhos de administração representam apenas $11 \%$ em detrimento a $89 \%$ de homens nessa posição.

Em relação a como se enxergam como profissionais, as respostas variaram entre: responsável, competente, capacitada e esforçada. Em relação ao empoderamento feminino e ao empreendedorismo feminino, de acordo com uma das entrevistadas: "As mulheres apoiando e incentivando umas às outras é fundamental para o desenvolvimento das mesmas e foi fundamental para a conquista dos nossos direitos" (E6).

Conforme o presidente do Sebrae Guilherme Afif Domingos, o movimento de empoderamento feminino vem se expandindo na política, na iniciativa privada e à frente dos 
negócios (SEBRAE, 2018). As mulheres estão se posicionando fortemente e marcando presença nos âmbitos econômico e social (PEQUENAS EMPRESAS \& GRANDES NEGÓCIOS, 2017).

Dentre as dificuldades citadas para se ter uma carreira empreendedora, destaca-se as questões financeiras para investir, a gestão do tempo para conciliar a vida pessoal com a vida profissional principalmente mulheres que possuem filhos e tem uma dupla jornada, o machismo e a falta de credibilidade no mercado de trabalho. Alguns indivíduos ficam com receio de que o negócio não irá para frente quando geridos por mulheres.

As mulheres ainda são as principais responsáveis pelas tarefas domésticas, e essa "dupla jornada" acaba sendo um peso a mais para elas. Somando as atividades do trabalho com as de dentro de casa, a jornada de trabalho acaba tendo cinco horas a mais comparado com a dos homens (PNAD, 2014 apud PINSKY e PEDRO, 2017). De acordo com Pinsky e Pedro (2017), em comparação com os homens, as mulheres brasileiras recebem menos e possuem mais responsabilidades familiares e domésticas mesmo obtendo mais oportunidades e direitos.

Conforme estudos realizados pelo Sebrae (2018), menos de 10\% das empresas lideradas por mulheres recebe investimento externo e poucas são consideradas de alto impacto. Se essas empresas recebessem um auxílio financeiro igual às dos negócios dirigidos por homens, seis milhões de empregos seriam gerados em apenas cinco anos.

Em relação a como enxergam o papel da mulher no mercado de trabalho, as respostas variaram-se entre serem fundamentais para o desenvolvimento econômico, social e cultural e serem um diferencial no mercado de trabalho por suas habilidades. "A mulher foi inserida no mercado de trabalho e é apta quanto qualquer outra pessoa a desenvolver uma função, o fato de ser mulher só reafirma a força", disse a entrevistada E15.

Entre as mudanças necessárias para que de fato se tenha um contexto de trabalho mais respeitoso e com igualdade de gêneros, falou-se mais sobre a conscientização dos indivíduos e educação da geração futura, para que venham sem pensamentos e atitudes que desvalorizam e desrespeitam as mulheres por serem mulheres e não cultuem o machismo. "Uma conscientização dos indivíduos em relação a importância do respeito e da igualdade de gêneros" disse a E15, enquanto a E2 disse acreditar que "a base para a mudança esteja na educação, desde criança já ensinar os filhos a tratar todos igualmente independente do gênero e a respeitar o próximo".

Segundo Strey e Cúnico (2016), o empoderamento feminino é fundamental para combater a desigualdade de gêneros, pois conscientiza e influencia a participação das mulheres na sociedade combatendo o domínio masculino e propagando a igualdade. Conforme Batliwala (1997, apud Marinho, 2015), o empoderamento feminino pode-se definir como um processo de superação da desigualdade de gênero.

Em relação ao aumento do número de empreendedoras no Brasil, as 15 entrevistadas concordam que há alguma relação com o empoderamento das mulheres/aumento de mulheres empoderadas. "Sim, estamos ganhando cada vez mais espaço graças aos movimentos feministas e ações de empoderamento, que estão surtindo efeitos na sociedade machista e tendem aproximar a sociedade da igualdade" (E13). "Mulheres empoderadas auxiliam no desenvolvimento do país e contribuem para a melhora da sociedade, uma mulher apoiando a outra e envolvendo os homens também para nos apoiar para alcançarmos uma sociedade mais justa" (E10). 
Referente a percepção em relação às mulheres empreendedoras, todas elogiaram os esforços delas para conquistar tal posição e se consideram exemplos para outras mulheres, já que conseguiram conquistar tal patamar profissional. As empresárias entrevistadas consideramse empoderadas, são a favor da igualdade de gêneros, de uma sociedade mais justa e livre de preconceito contra as mulheres. Na opinião de uma das empresárias: "Daqui 10 anos o que eu espero é maior inclusão das mulheres no mercado de trabalho, principalmente, em cargos que historicamente sempre foram ocupados por homens, igualdade salarial e menos preconceito" (E15).

De acordo com Strey e Cúnico (2016), o empoderamento promove a inclusão social. Empoderar significa conquistar espaço, vez e voz, de forma com que cada indivíduo obtenha autonomia e capacidade de fazer escolhas sociais, políticas e econômicas, auxiliando os indivíduos que não possuem tantos recursos.

\section{$5 \quad$ Considerações Finais}

A pesquisa apresentou como objetivo geral relatar como mulheres empreendedoras percebem o próprio desenvolvimento e o empoderamento feminino na sociedade contemporânea , a partir da elucidação dos seguintes objetivos específicos: (I) identificar quais as dificuldades enfrentadas por mulheres empreendedoras no mercado de trabalho; (II) demonstrar a importância do empoderamento das mulheres para a construção de uma sociedade igualitária no quesito social/econômico; e por fim, correlacionar o empoderamento feminino com o desenvolvimento das mulheres empreendedoras.

Quanto ao primeiro objetivo específico, identificou-se que, as questões financeiras para investir, a gestão do tempo para conciliar a vida pessoal com a vida profissional principalmente mulheres que possuem filhos e tem uma dupla jornada, o machismo e a falta de credibilidade no mercado de trabalho como algumas das maiores dificuldades.

Notou-se que as mulheres precisam se esforçar muito e tendem a demorar mais que os homens para conseguirem atingir um cargo elevado dentro das grandes empresas, dentro os motivos, por terem que provar que são realmente capazes e por muitas empresas possuírem uma cultura organizacional machista. No ramo do empreendedorismo, as mulheres apesar de estarem avançando no mercado e ganhando mais espaço, vez e voz na sociedade, não recebem tantos investimentos em suas empresas, além disso, tendem a enfrentar dificuldades quando o assunto é conciliar vida profissional com a pessoal e gestão de tempo. É notável que a maioria das mulheres possuem uma dupla jornada pois além de trabalharem fora, por serem donas de casa e assim como algumas das entrevistadas, mães e esposas, possuem tarefas rotineiras que aumentam a carga horária diária de trabalho.

Evidenciou-se que apesar de crescente o número de mulheres assumindo posições de gerência em grandes empresas e na frente de novos negócios, os homens ainda possuem maior presença em cargos mais estratégicos nas empresas e recebem em sua maior parte, salários mais elevados mesmo estando na mesma posição que uma mulher.

Quanto ao segundo objetivo específico constatou-se que o empoderamento feminino é fundamental para combater a desigualdade de gêneros, pois conscientiza e influencia a participação das mulheres na sociedade combatendo o domínio masculino e propagando a igualdade, promovendo uma desconstrução cultural na sociedade, estimulam uma série de 
benefícios como a igualdade salarial e de oportunidades no mercado de trabalho, acesso igualitário à educação independente do gênero, além de promover a desvinculação da imagem de mulheres apenas como donas de casa, trazendo reflexos positivos para as próximas gerações.

Em relação ao terceiro objetivo específico, percebeu-se que o impacto dos movimentos feministas frente ao empoderamento das mulheres em uma sociedade que possui raízes machistas e repressoras vêm gerando efeitos positivos e beneficiando na construção de uma sociedade mais justa e igualitária. Impactos positivos no âmbito cultural, social e econômico podem ser notados com o auxílio do empoderamento feminino. Nos últimos anos, mais mulheres estão frequentando as universidades, conquistando mais espaço no mercado de trabalho, chegando aos poucos no topo das grandes empresas, abrindo suas próprias, além disso, toda essa mudança auxilia no desenvolvimento da geração futura. Os meninos e as meninas tendem a vir mais conscientes, as meninas tendem a se sentir mais à vontade para escolher a profissão que quiserem seguir sem sofrerem com julgamentos, tendem a possuir mais oportunidades de emprego com salários e tratamentos igualitários aos do sexo oposto.

Salienta-se, que além dos objetivos específicos, foi possível responder ao problema de pesquisa proposto, uma vez que, as mulheres empreendedoras entrevistadas relataram algumas das dificuldades enfrentadas e esforços para chegarem aonde estão profissionalmente. Essas mulheres se consideram empoderadas e apoiam as ações de empoderamento feminino, pois acreditam ser relevantes para a promoção de uma sociedade mais igualitária, com mais oportunidades para as mulheres assim como os homens possuem e sem machismo.

Os resultados da pesquisa demonstram que as ações de empoderamento feminino auxiliam no desenvolvimento das mulheres empreendedoras, que estão aos poucos ganhando espaço, vez e voz dentro e fora do mercado de trabalho. Entretanto, embora as 15 entrevistadas acreditem que o empoderamento feminino seja fundamental para o desenvolvimento das mulheres no mercado de trabalho, percebe-se que os homens ainda possuem mais oportunidades profissionais e maior possibilidade de progredir na carreira do que elas. Se faz necessário uma promoção da conscientização dos indivíduos frente ao problema social da desigualdade de gêneros.

Por fim, para estudos futuros recomenda-se que essa pesquisa seja ampliada, contendo uma amostra maior, assumindo também uma abordagem quantitativa, podendo assim, possibilitar análise acerca de índices de desenvolvimento do empreendedorismo feminino no decorrer dos anos comparando entre as próprias mulheres divididas por raça ou nacionalidade.

A pesquisa desenvolvida mostrou-se relevante, pois tratou de um tema social que é o empoderamento feminino correlacionado ao empreendedorismo na percepção de mulheres empreendedoras. Notou-se como esse fenômeno social vem auxiliando as minorias no decorrer dos anos, promovendo aos poucos a igualdade entre homens e mulheres no mercado de trabalho e fora dele.

\section{REFERÊNCIAS}

ALVIN, Paulo, 2012. Empreendedorismo Feminino - Sebrae. Disponível em: $<$ http://www.sebraemercados.com.br/empreendedorismo-feminino/>. Acesso em: 19 de abril 2018.

BIAGIO, Luiz Arnaldo. Empreendedorismo: construindo seu projeto de vida - Barueri, SP: Manole, 2012. 
BORELLI, Andrea e MATOS, Maria Izilda. "Espaço Feminino no Mercado Produtivo". Livro: Nova História das mulheres. Organizadoras: Carla Bassanezi Pinsky e Joana Maria Pedro. - 1.ed. - São Paulo: Contexto, 2012, p.126-146.

CABRAL, Márcia Regina. O mercado de trabalho na década de 90: um mundo em transformação, 1999.

CAMARGO, Orson. "A mulher e o mercado de trabalho". Brasil Escola, 2013. Disponível em $<$ https://brasilescola.uol.com.br/sociologia/a-mulher-mercado-trabalho.htm $>$. Acesso em 11 de abril 2018.

CHIARA, I. D. et al. Normas de documentação aplicadas à área de Saúde. Rio de Janeiro: Editora E-papers, 2008. Disponível em: <https://guiadamonografia.com.br/pesquisabibliografica/>. Acesso em: 14 de outubro 2018.

COSTA, Luzia, 2018 - CEO do Grupo Cetro. Mulheres empreendedoras enfrentam grandes desafios no mundo dos negócios. Publicado em: 27 de março 2018. Disponível em: $<$ http://www.administradores.com.br/noticias/cotidiano/mulheres-empreendedoras-enfrentamgrandes-desafios-no-mundo-dos-negocios/124049/>. Acesso em: 19 de abril 2018.

DEGEN, Ronald Jean, O Empreendedor: Empreender como opção de carreira - São Paulo: Pearson Prentice Hall, 2009 p.8.

GIL, Antônio Carlos. Método e técnicas de pesquisa social. $6^{a}$. ed. São Paulo: Atlas S.A, 2008. Disponível em: <https://guiadamonografia.com.br/pesquisa-de-campo/>. Acesso em: $26 \mathrm{de}$ maio 2018.

GOMES, CRISTINA, 2017. "Por que o empoderamento feminino favorece uma sociedade inteira?". Disponível em: <http://mulherlider.com.br/blog/por-que-o-empoderamento-femininofavorece-uma-sociedade-inteira/>. Acesso em: 06 de agosto 2018.

GLOBAL ENTREPRENEURSHIP MONITOR - GEM, 2015. Mulheres Empreendedoras. Publicado por: Revista Pequenas Empresas e Grandes Negócios, 08 marços 2016. Disponível em: <https://revistapegn.globo.com/Mulheres-empreendedoras/noticia/2016/03/10-exemplosde-empreendedoras-para-te-inspirar.html>. Acesso em: 10 de março 2018.

GLOBAL ENTREPRENEURSHIP MONITOR - GEM, 2016. Publicado por: Revista Pequenas Empresas e Grandes Negócios, "Mulheres no Comando - Aumenta a participação das mulheres no movimento do empreendedorismo". Publicado em: 13/12/2017. Disponível em:

$<$ https://revistapegn.globo.com/Publicidade/Novo-CitroenJumpy/noticia/2017/12/mulheres-no-comando.html>. Acesso em: 18 de abril 2018.

GLOBAL ENTREPRENEURSHIP MONITOR - GEM, 2016. Os desafios da mulher empreendedora. Publicado por: Portal Sebrae em 05 de março 2018. Disponível em: $<$ http://www.sebrae.com.br/sites/PortalSebrae/artigos/os-desafios-da-mulher-

empreendedora,e74ab85844cb5510VgnVCM1000004c00210aRCRD > . Acesso em: 18 de abril 2018

INSTITUTO ETHOS, Perfil Social, Racial e de Gênero das 500 maiores empresas do brasil e suas ações afirmativas. 2016. Disponível em <http://www.onumulheres.org.br/wpcontent/uploads/2016/04/Perfil_social_racial_genero_500empresas.pdf $<$. Acesso em: 16 nov. 
de 2018.

MANDELLI, Lívia. Liderança nua e crua: decifrando o lado masculino e feminino de liderar. Petrópolis, RJ: Vozes, 2015.

MEDEIROS, João Bosco. Redação Científica: a prática de fichamentos, resumos, resenhas. São Paulo: Atlas, 2000. Disponível em: $<$ https://guiadamonografia.com.br/fontes-primarias-esecundarias/>. Acesso em 29 de agosto 2018.

MELO, et. al. "Em busca de Técnicas Complementares em Pesquisa Qualitativa no Campo da Administração". Encontro de Ensino e Pesquisa em Administração e Contabilidade. Recife, 2007.

MORENO. Rachel. O Sexismo custa caro. In: ETHOS - Perfil Social, Racial e de Gênero das 500 Maiores Empresas do Brasil e Suas Ações Afirmativas. São Paulo, maio de 2016. p. 22 $-23$.

PINSKY, Carla Bassanezi e PEDRO, Joana Maria. "Mulheres" - O Brasil no contexto: 19872017/organizado por Jaime Pinsky; José de Souza Martins... [et al.]; ilustrado por Sergio Kon. - São Paulo: Contexto, 2017 p.111 - 122.

PEQUENAS EMPRESAS \& GRANDES NEGÓCIOS. "Mulheres no Comando - Aumenta a participação das mulheres no movimento do empreendedorismo". Publicado em: 13/12/2017. Disponível em: $\quad<$ https://revistapegn.globo.com/Publicidade/Novo-CitroenJumpy/noticia/2017/12/mulheres-no-comando.html>. Acesso em: 18 de abril 2018.

PRODANOV, Cleber Cristiano; FREITAS, Ernani Cesar De. Metodologia do trabalho científico: Métodos e Técnicas da Pesquisa e do Trabalho Acadêmico. $2^{\mathrm{a}}$. ed. Novo Hamburgo: Universidade Freevale, 2013. Disponível em: $<$ https://guiadamonografia.com.br/pesquisadescritiva/>. Acesso em: 27 de maio 2018.

SARDENBERG, Cecília M. B., 2009 p.6. Conceituando "Empoderamento" na Perspectiva Feminista. Repositório Institucional UFBA. Disponível em: $<$ https://repositorio.ufba.br/ri/bitstream/ri/6848/1/Conceituando $\% 20$ Empoderamento $\% 20 \mathrm{na} \%$ 20Perspectiva\%20Feminista.pdf $>$. Acesso em 10 de março 2018.

SEBRAE, 2015. Governo do Brasil: Empreendedorismo feminino cresce 34\% em 14 anos. Disponível em: <http://www.brasil.gov.br/economia-e-emprego/2017/03/empreendedorismofeminino-cresce-34-em-14-anos>. Acesso em: 12de março 2018.

SEBRAE, 2018. Mulheres empreendem mais que os homens. Publicado em 06 de março 2018. Disponível em: $<$ http://www.agenciasebrae.com.br/sites/asn/uf/NA/mulheresempreendem-mais-que-os-homens, 00705bd2fb7f1610VgnVCM1000004c00210aRCRD>. Acesso em: 24 de abril 2018.

SEBRAE, 2018. Os Desafios da Mulher Empreendedora. Disponível em: $<$ http://www.sebrae.com.br/sites/PortalSebrae/artigos/os-desafios-da-mulherempreendedora,e74ab85844cb5510VgnVCM1000004c00210aRCRD $>$. Publicado em: 05 de março 2018. Acesso em: 18 de abril 2018. 
STREY, Marlene Neves e CÚNICO, Sabrina Daiana. Teorias de gênero: feminismos e transgressão. Série Gênero e Contemporaneidade; v.11, p. 13-18 - Porto Alegre: EDIPUCRS, 2016.

TOMAINO, Bianca, et al. Metodologia científica: fundamentos, métodos e técnicas. Coordenação: Vanderlei Martins, Cleyson de Moraes Mello. Rio de Janeiro: Freitas Bastos, 2016. 